\title{
1. Business not-as-usual to achieve SDGs under climate change
}

\section{Paul Shrivastava}

\section{INTRODUCTION}

\section{The Great Acceleration, Planetary Boundaries, and the Anthropocene}

Working toward global sustainability necessitates planetary scale thinking and research. We need a planetary mindset that encourages thinking of sustainability in terms of providing food, water and energy for the 9-10 billion people expected to be on the earth by 2050. And this must be done without destroying the ecosystems that sustain life. The signing of the international agreements on Sustainable Development Goals (SDGs; September 2015) and Paris Accord on Climate Change (December 2015) reflect a global consensus on how we can achieve sustainability.

In the past 40 years the natural sciences have greatly increased our understanding of the planet we live on. International research programs on global environmental change have clearly documented the increasing impacts of humans on natural systems. Collectively they point to the need for rethinking economic and business activities to meet the needs of present and future generations. Three concepts are important for understanding the evolving relationships between humans and nature. We summarize them here in the concepts of the Great Acceleration, Planetary Boundaries, and the Anthropocene.

The great acceleration of human impacts on nature are captured in a study by Steffen et al. (2015a). Tracking and charting a variety of social and ecosystem trends between 1750 and 2010, this study shows some stark developments (Figure 1.1).

The social trends (shown on left) in growth of population, Gross Domestic Product (GDP), Foreign Direct Investment, Primary Energy Use, Large Dams, Water Use, Fertilizer Consumption, Paper Production, Urban Population, Transportation Telecommunication, and International Tourism seem to follow the similar patterns. On all these variables the growth between 1750 and 1950 is slow and steady. From 1950 onwards, 


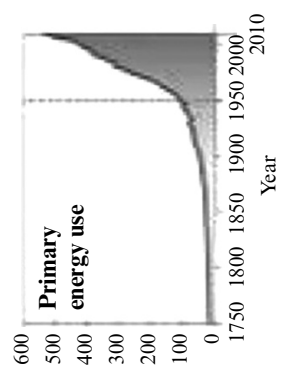

(f̈) ข[nọ̣exg
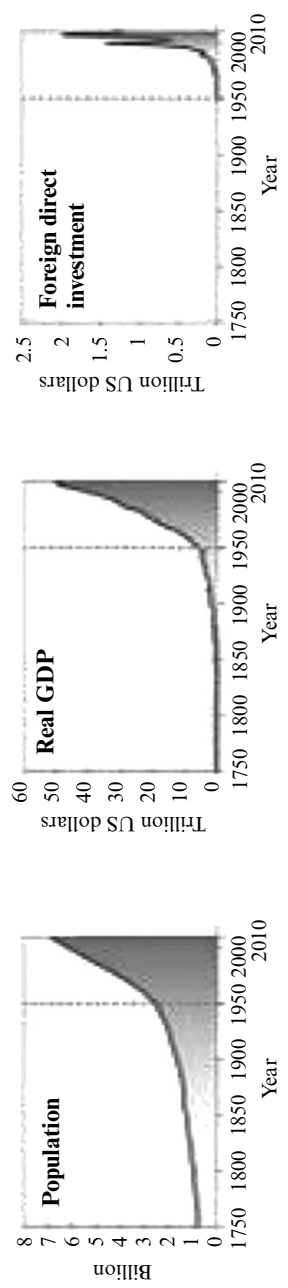
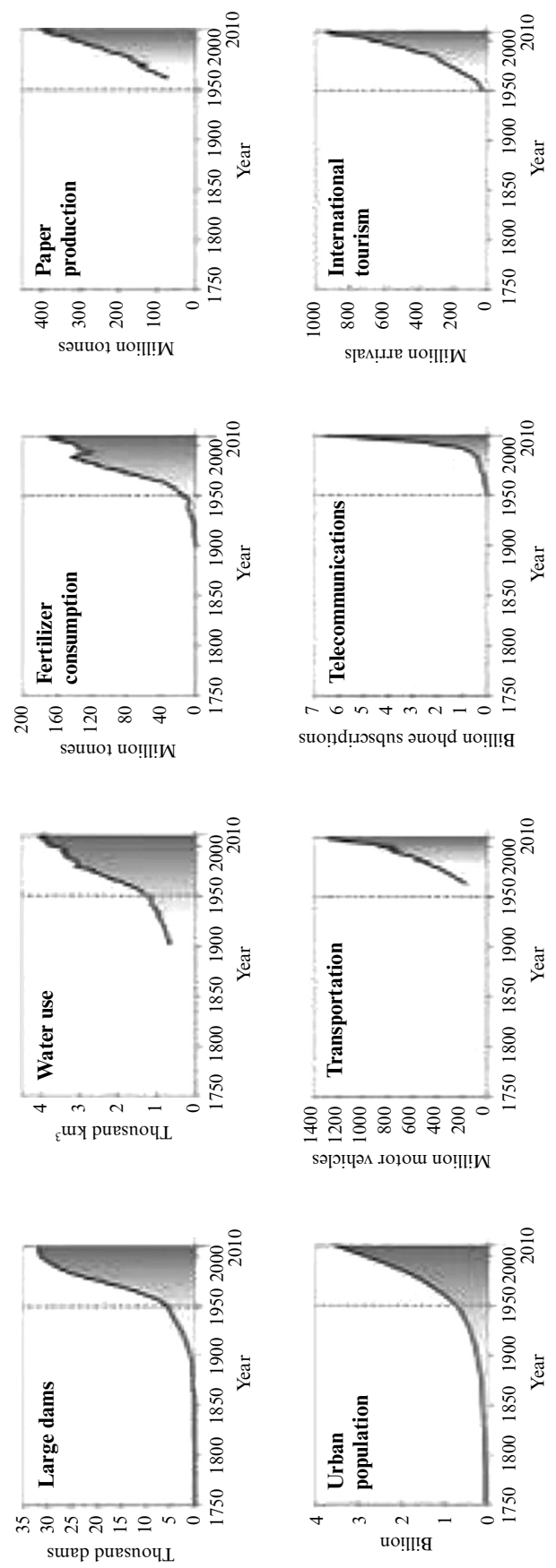

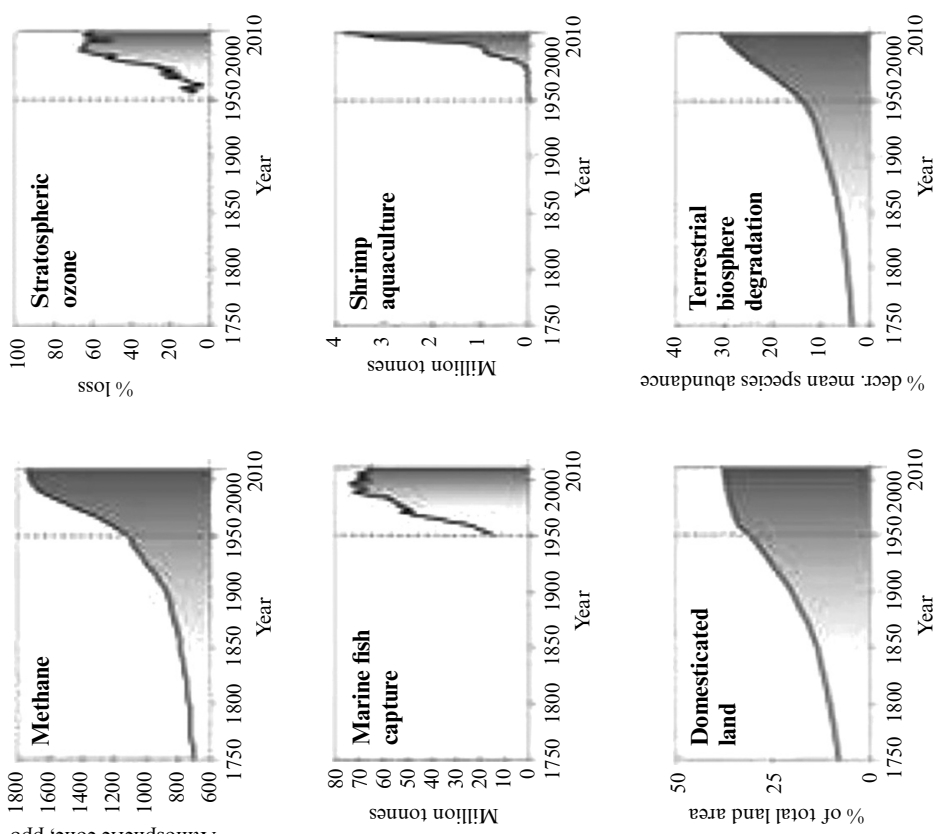

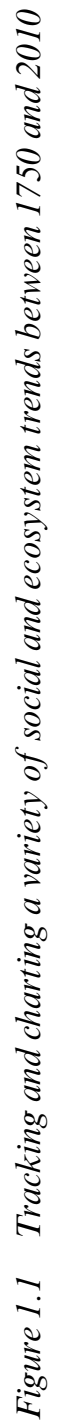

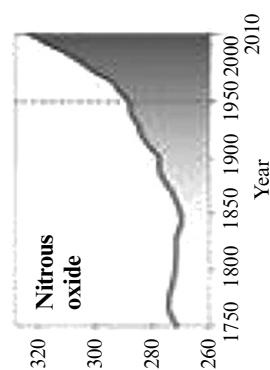

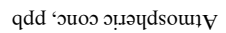

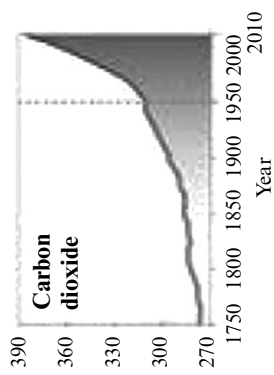

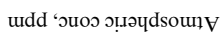

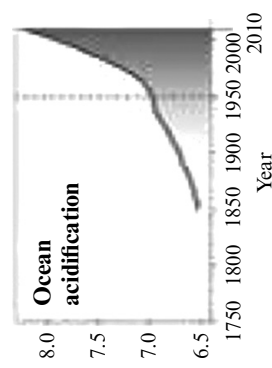

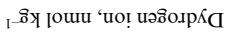

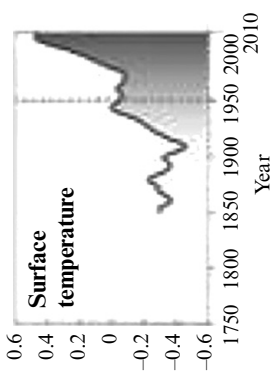

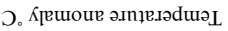

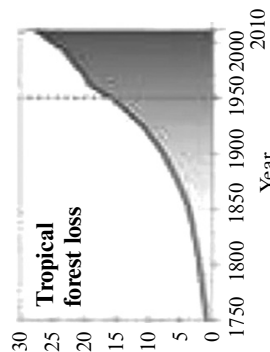

(घวI) ) SSO \%

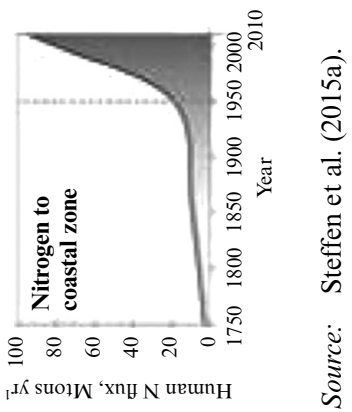


there is a jump in the rate of growth and we see exponential growth giving a hockey stick shape curve for all these variables. The ecosystems trends during the same period (shown on the right) in the growth of Carbon Dioxide, Nitrogen Oxide, Methane, Stratospheric Ozone, Earth Surface Temperatures, Ocean Acidification, Marine Fish Capture, Shrimp Aquaculture, Nitrogen to Coastal Zones, Tropical Forest Loss, Domesticated Lands, and Terrestrial Biosphere degradation seem to mimic the same pattern. There is slow growth until 1950, followed by exponential growth thereafter. The period of 1950 onwards is a period of the "great acceleration" of human impacts on natural ecosystems.

The level of this human-caused impact is best indicated by another recent study by Rockstrom et al. (2009) that proposed the concept of planetary boundaries. This study tracked earth ecosystem performance on nine critical variables that are necessary to sustain life on earth (Figure 1.2).

These include Climate Change, Novel Entities, Stratospheric Ozone Depletion, Atmospheric Aerosol Loading, Ocean Acidification, Biogeochemical Flows (Phosphorus, Nitrogen), Freshwater Use, Land System Change, and Biosphere Integrity (Genetic Diversity). The study found that for biogeochemical flows of phosphorus and nitrogen and genetic diversity we have breached safe operating boundaries. For the novel entities and atmospheric aerosol loading variables, we do not have sufficient data to judge impacts. On climate change and land system change variables, we are in the zone of uncertainty. If we continue to operate with a business-as-usual attitude we are highly likely to breach additional boundaries in coming years. The Paris Accord on Climate Change seeks to limit the carbon emissions into the atmosphere to keep the rise in global temperatures to under $2^{\circ} \mathrm{C}$. Since the major source of carbon is from the burning of fossil fuels for energy, any pathway to controlling carbon must address energy demand and production.

It should also be noted that we have reached the current risky levels of human impacts on nature with only 7.2 billion people on earth. Moreover, almost 2 billion people (mostly in poorer countries) are currently consuming under US\$2 per day, and aspire to improve their standards of living. On the other hand, 50 percent of wealth is owned by less than 1 percent of the population, creating immense inequalities. Increasing consumption risks further degradation of ecosystems. Ever-increasing consumption as a measure of success creates a vicious cycle of human consumption and ecosystem destruction. Kate Raworth (2012) articulated a "safe and just space" for humanity within planetary boundaries, represented in Figure 1.3. It expresses the need to provide adequate food, water, energy, income, education resilience, voice jobs, health, and gender and social equity for all while staying within planetary 


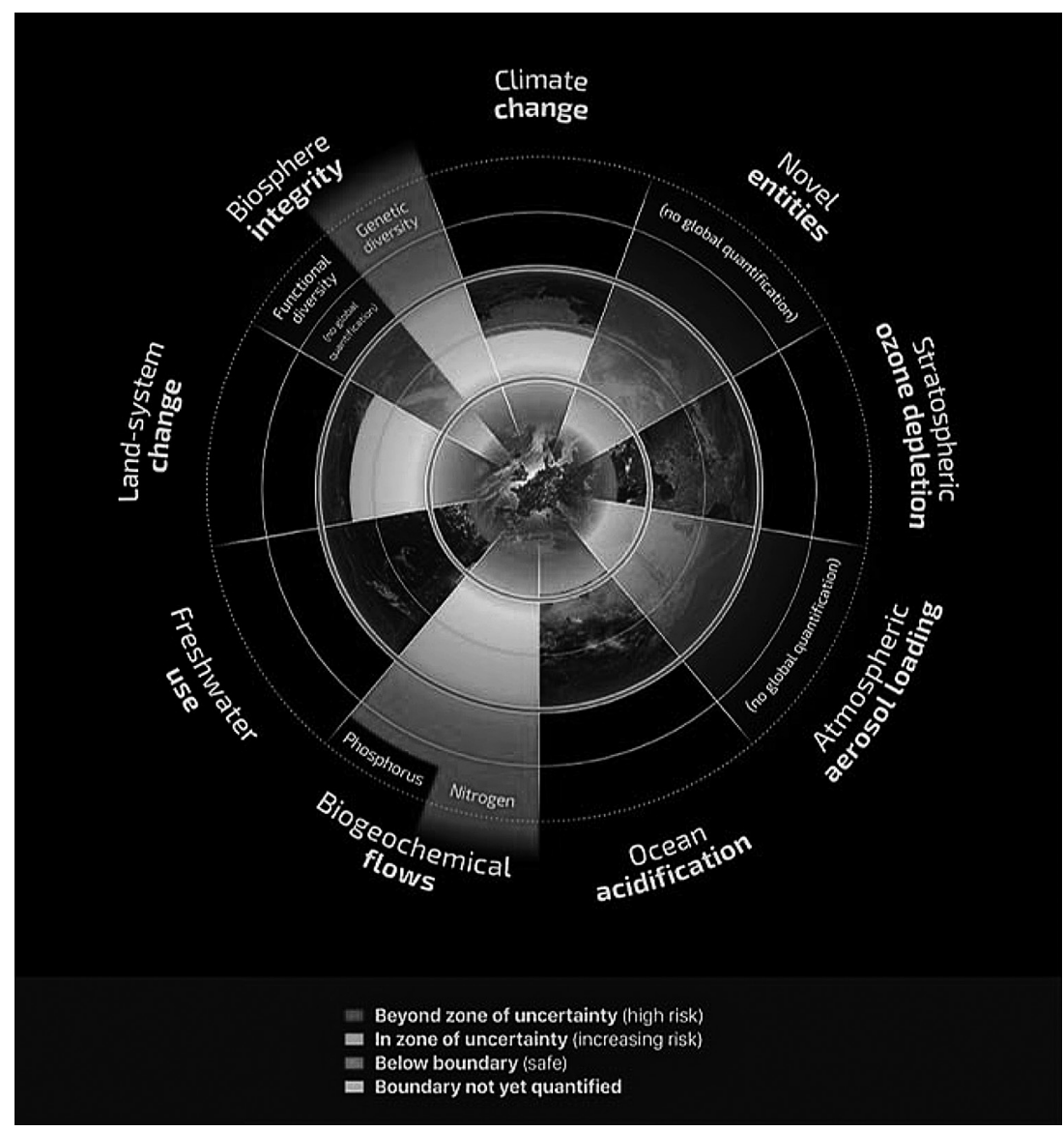

Source: Steffen et al. (2015b).

Figure 1.2 Planetary boundaries - a safe operating space for humanity

boundaries and averting catastrophic climate change. This requires human agency and human choices about our life styles, consumption patterns, production systems, and infrastructures. This is the era of the "Anthropocene" where human activities have a greater impact on nature's cycle than nature itself and where human choices will determine nature's long-term viability for supporting life. 


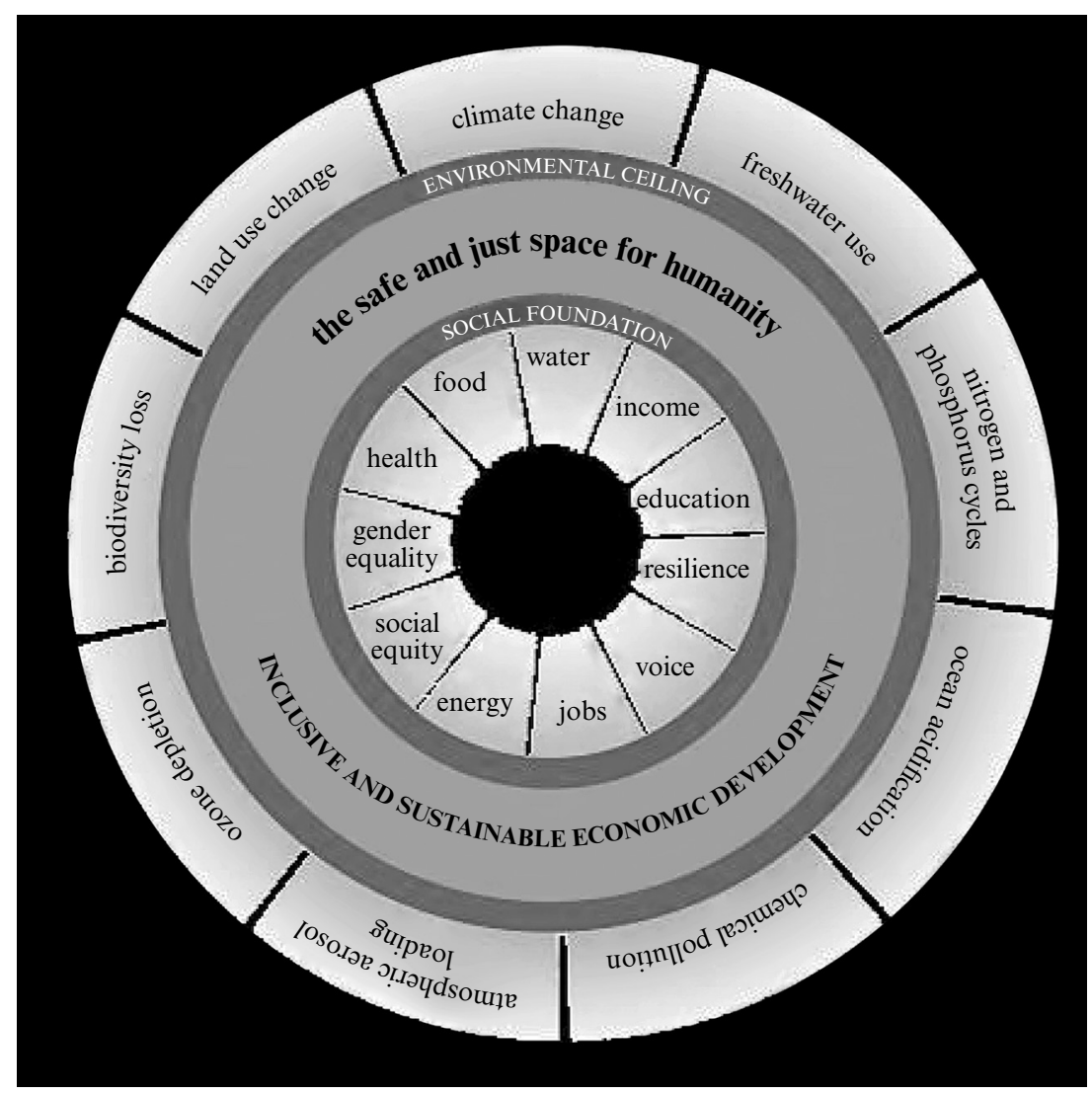

Source: Raworth (2012).

Figure 1.3 A safe and just space for humanity to thrive in: a first illustration

\section{SUSTAINABLE DEVELOPMENT SOLUTIONS}

Accelerating impacts of human activities on nature are a source of potential existential threats. The solutions to these threats lie in implementing SDGs agreed to by 195 nations under the then-United Nations umbrella (United Nations, 2015). These goals are listed in Table 1.1.

The SDGs represent a global consensus among nations whose leaders in September 2015 signed an agreement to implement them. They serve as an agenda for the next 15 years of economic and social development in 


\section{Table 1.1 The 17 Sustainable Development Goals}

Goal 1 End poverty in all its forms everywhere

Goal 2 End hunger, achieve food security and improved nutrition, and promote sustainable agriculture

Goal 3 Ensure healthy lives and promote well-being for all at all ages

Goal 4 Ensure inclusive and equitable quality education and promote lifelong learning opportunities for all

Goal 5 Achieve gender equality and empower all women and girls

Goal 6 Ensure availability and sustainable management of water and sanitation for all

Goal 7 Ensure access to affordable, reliable, sustainable, and modern energy for all

Goal 8 Promote sustained, inclusive and sustainable economic growth, full and productive employment, and decent work for all

Goal 9 Build resilient infrastructure, promote inclusive and sustainable industrialization, and foster innovation

Goal 10 Reduce inequality within and among countries

Goal 11 Make cities and human settlements inclusive, safe, resilient, and sustainable

Goal 12 Ensure sustainable consumption and production patterns

Goal 13 Take urgent action to combat climate change and its impacts

Goal 14 Conserve and sustainably use the oceans, seas and marine resources for sustainable development

Goal 15 Protect, restore, and promote sustainable use of terrestrial ecosystems, sustainably manage forests, combat desertification, and halt and reverse land degradation, and halt biodiversity loss

Goal 16 Promote peaceful and inclusive societies for sustainable development, provide access to justice for all and build effective, accountable and inclusive institutions at all levels

Goal 17 Strengthen the means of implementation and revitalize the global partnership for sustainable development

the context of climate change. Many nations such as China, India, Japan, Switzerland, Sweden, and Germany, among others, have translated the SDGs for their respective countries. They have established national missions and provincial-level plans providing a policy framework guiding their implementation. There was great support for the SDGs from the business/ corporate sector. Most businesses, especially large multinational corporations, understand what is at stake and have expressed their commitment to rethink their strategies and investments. 


\section{Business Opportunities in Implementing Sustainable Development Goals}

Business as the main economic engine of society can play a central role in implementation of the SDGs. The Business \& Sustainable Development Commission (2017) suggests that achieving these goals will offer market opportunities worth US\$12 trillion by 2030. But this business prize will not materialize with a business-as-usual approach. It will require innovative thinking and deep restructuring of products/services and business models.

Modern corporations as independent limited-liability legal identity, maximizing shareholder value and operating within free capital markets, have been successful in creating enormous wealth. But this way of wealth creation had unintended consequences for the natural environment and for social and economic equality. Investors and entrepreneurs are now absorbing more risk than ever before. This greater appetite for risk, along with the technological innovations and unparalleled population growth, have led to prosperity and well-being for many. But it has also created a highly unequal world. One percent of the wealthiest individuals hold greater wealth than the bottom 50 percent combined. To address these issues, it is necessary for business corporations to rethink their basic approach to sustainability and innovate new business models.

In parallel with the massive growth of the global economy, the ability of science to examine and monitor natural and social changes has also improved dramatically. This has led to a greater understanding of natural, social, and technological trends. It also points to the need for solutions that combine science with business logic. The focus of science in the past was on observing and analyzing earth's systems, pollution, population, consumption, biodiversity, and biogeochemical trends, among other phenomena. Scientific expertise operated within narrow disciplinary fields, and scientific knowledge became somewhat detached from its relevance to decision makers and society. It is in this milieu that Future Earth was formed to encourage transdisciplinary solutions oriented science. Future Earth is a network of 50,000 scientists who study all aspects of global environmental changes. It combines the intellectual and programmatic resources of three decades-long research programs: the International Geosphere Biosphere Program, DIVERSITAS, and the International Human Dimensions Program. It is sponsored by the International Science Council, International Social Science Council, and numerous United Nations bodies including United Nations Educational, Scientific and Cultural Organization (UNESCO), United Nations University (UNU), United Nations Environment Programme (UNEP), Sustainable Development Solutions Network (SDSN), and the Belmont Forum group of science funding agencies, among others. 


\section{FUTURE EARTH'S KNOWLEDGE-ACTION NETWORKS}

One tool for transitioning from studying problems in isolated and siloed disciplinary scientific communities is developing networks of research and action that work scientifically to solve real-world global sustainability challenges. Future Earth's Knowledge-Action Networks (KAN) are such networks. They are fruitful collaborations that promote transdisciplinary, stakeholder engaged, co-designed, and co-produced scientific solutions. They seek to develop knowledge to inform scientifically grounded global sustainability solutions through collaboration between business leaders, scientists, policy makers, non-governmental organizations (NGOs), and decision makers at all levels.

These KANs benefit from being aligned with the values and tradeoffs articulated by the SDGs. With this alignment, the networks are flexible enough to encompass everything from communication about disciplinary and technical issues to decision-making around large, multi-stakeholder questions. They foster candid conversations required to address global issues. The collaborations of diverse individuals adopt an open and sharing mindset. Experts in fields like research, policy, and business engage each other to overcome their own limitations and commit to learning, un-learning, and re-learning collectively. KANs aspire to global skill mobilization and development, which requires patience and resilience to allow concepts time to morph from typical business, grant, and political cycles to that of the long-term health of the planet and its species.

Continuing with business-as-usual is not an option if we want to achieve the SDGs by 2030. Future Earth's KANs allow businesses to leverage existing global sustainability science. Through co-design and co-production of knowledge with end users they encourage collaborators to ask appropriate questions, execute research, and implement solutions. Nine KANs are being established as depicted in Figure 1.4.

To facilitate these KANs, Future Earth operates an online platform called the Open Network (network.futureearth.org). Here, professionals and organizations from around the world can engage and collaborate around the SDGs and the Future Earth 2025 Vision of building transdisciplinary global sustainability science. The platform encourages brainstorming, process planning, information flows, collaboration, and dialogue. By moving beyond closed email chains, siloed scientific inquiries, and uniformly created projects, groups with diverse backgrounds, orientations, beliefs, and visions of the futures can leverage digital tools to create timely, actionable knowledge.

Another important task in the Anthropocene will be communication of 


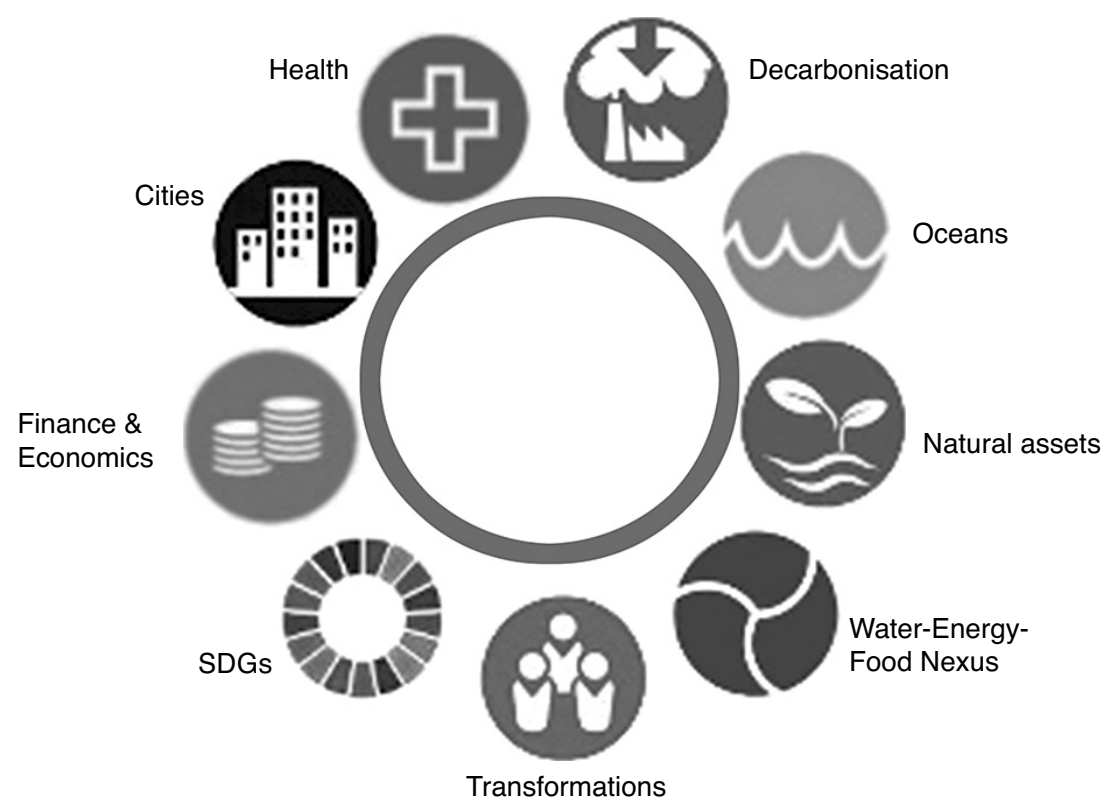

Source: Author.

Figure 1.4 Future Earth Knowledge-Action Networks

scientific knowledge to the public that will empower them to invoke local actions. Scientific communications will need to support decision-making beyond boardrooms into the public sphere. Communications will need to go beyond using traditional communication tools such as reports, publications, white papers, executive briefs, and PowerPoint presentations to new forms of visualization, gamification, and storification of scientific results. The economical, scientific, and spiritual tradeoffs associated with issues surrounding dramatic natural events, such as record shrinking of Arctic sea ice, catastrophic drought across western North America, and the "mass-bleaching" of 35 percent of coral in the Great Barrier Reef, require new styles of communication and decision-making. The Future Earth Media Lab creates digital products that drive cognitive and emotional connections between people and their natural environment. They develop immersive experiences for engaging sustainability at a personal level. Through personal engagement and a deepening sense of personal responsibility, it is possible to change behaviors of individuals and groups. It brings the "choose your own adventure" novel methodology to business 
and civil society, leveraging the power of augmented and virtual reality, enhanced computer models and simulation, along with thoughtful artistic, meditative, and naturalistic practices. Such communications services invoke empathy for global changes and knowledge-informed innovative actions by businesses, governments, and societies.

To develop these new forms of collaboration, communication, and learning we embrace the software development model of being in constant "Beta Mode." With the ubiquity of world-class massive open online courses (MOOCs), individuals have the resources to become exposed and fluent in the knowledge needed to relate to new colleagues, markets, ideas, and issues. Putting knowledge into action will continue to rely on the communication and sharing of individuals' interpretation of how and what they are learning. Evaluation must therefore move beyond the isolated learning associated with typical examinations and professional designations, and instead it must embrace learning in real time, both at the computer-model level and within real-world problem-solving situations.

\section{KANs - Sustainable Development Goals Map}

Future Earth's KANs collectively support all the SDGs, offering a robust scientific base for their implementation. Table 1.2 shows associations and focus between SDGs and eight KANs (the Decarbonization KAN is not included because it is in early stages of formation).

KANs are forming in a bottom-up manner among scientists, researchers, policy makers, participants in civil society, businesses, and entrepreneurs. Aligned with the values of the SDGs, participants engage voluntarily in open and inclusive communications, committed to continuing selfeducation and organizational improvements (Stafford-Smith et al., 2016).

\section{TOWARD PLANETARY MANAGEMENT}

The bottom line for researchers and practitioners is to acknowledge that we are living in a fundamentally different world. Knowledge for action is needed for implementing SDGs under climate change. Business researchers and corporate managers can get involved with the KANs to remain at the leading edge of our scientific understanding of sustainability issues and developing practical evidence-based solutions. Business-as-usual will not work. The business-as-usual mentality harms the environment and creates new emerging risks to society. The planet is a finite resource and has real biophysical limits subject to laws of thermodynamics. Management and Business Studies disciplines have been preoccupied with understanding the management of 


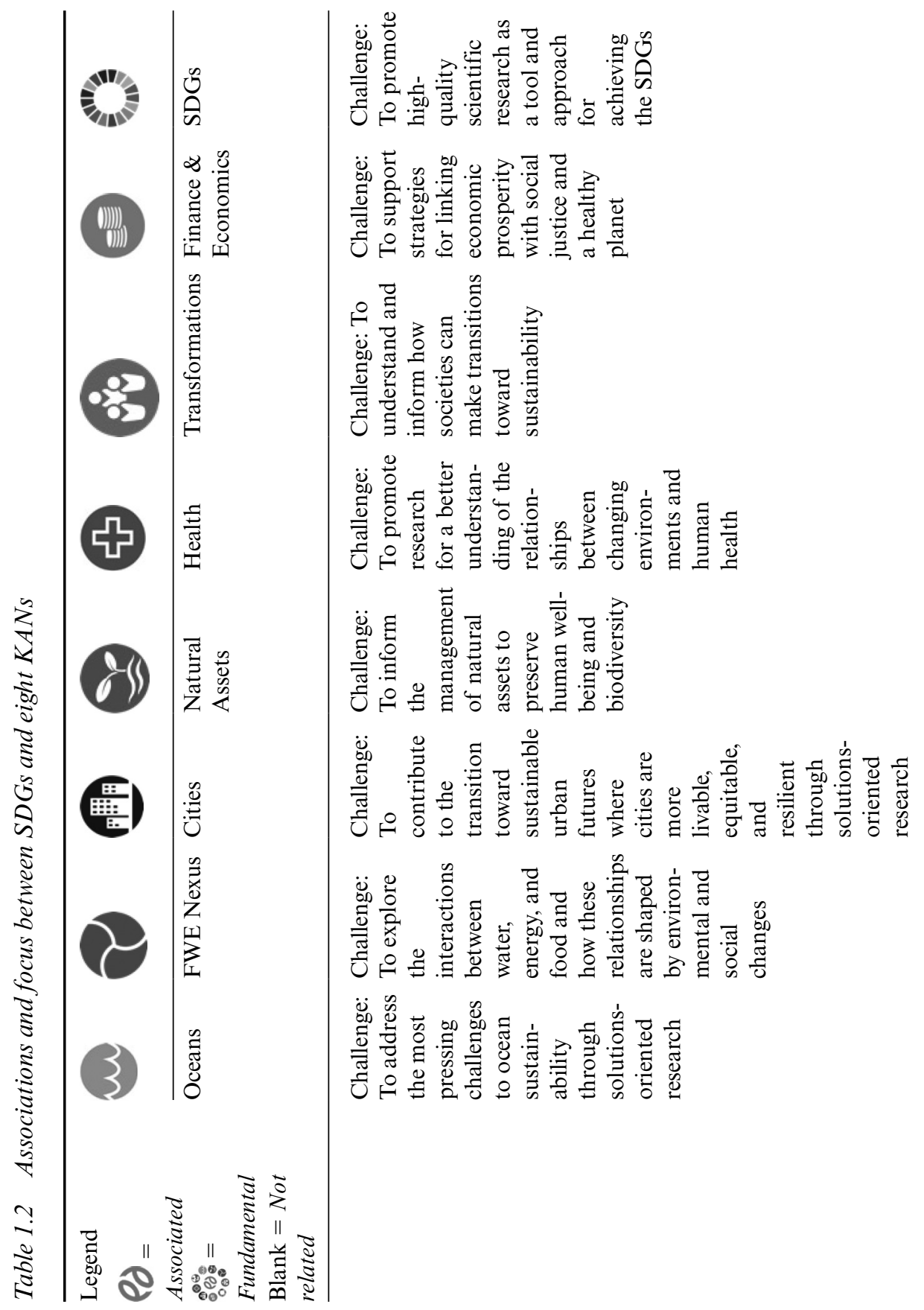




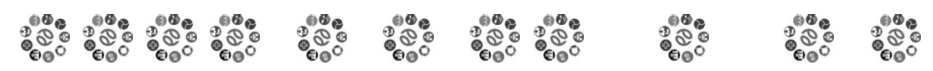

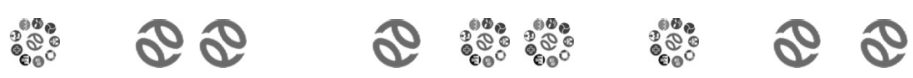

5 56 5 ะ.

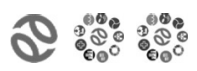

2

:

2

89

๕.85

2

เேะே

2

2

:

Z

คั

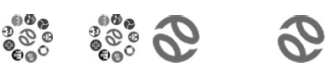

2

产

๑ேะ

๕ะ8

2

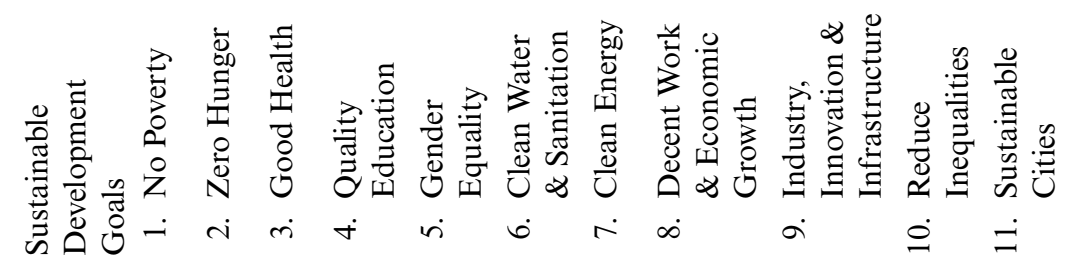




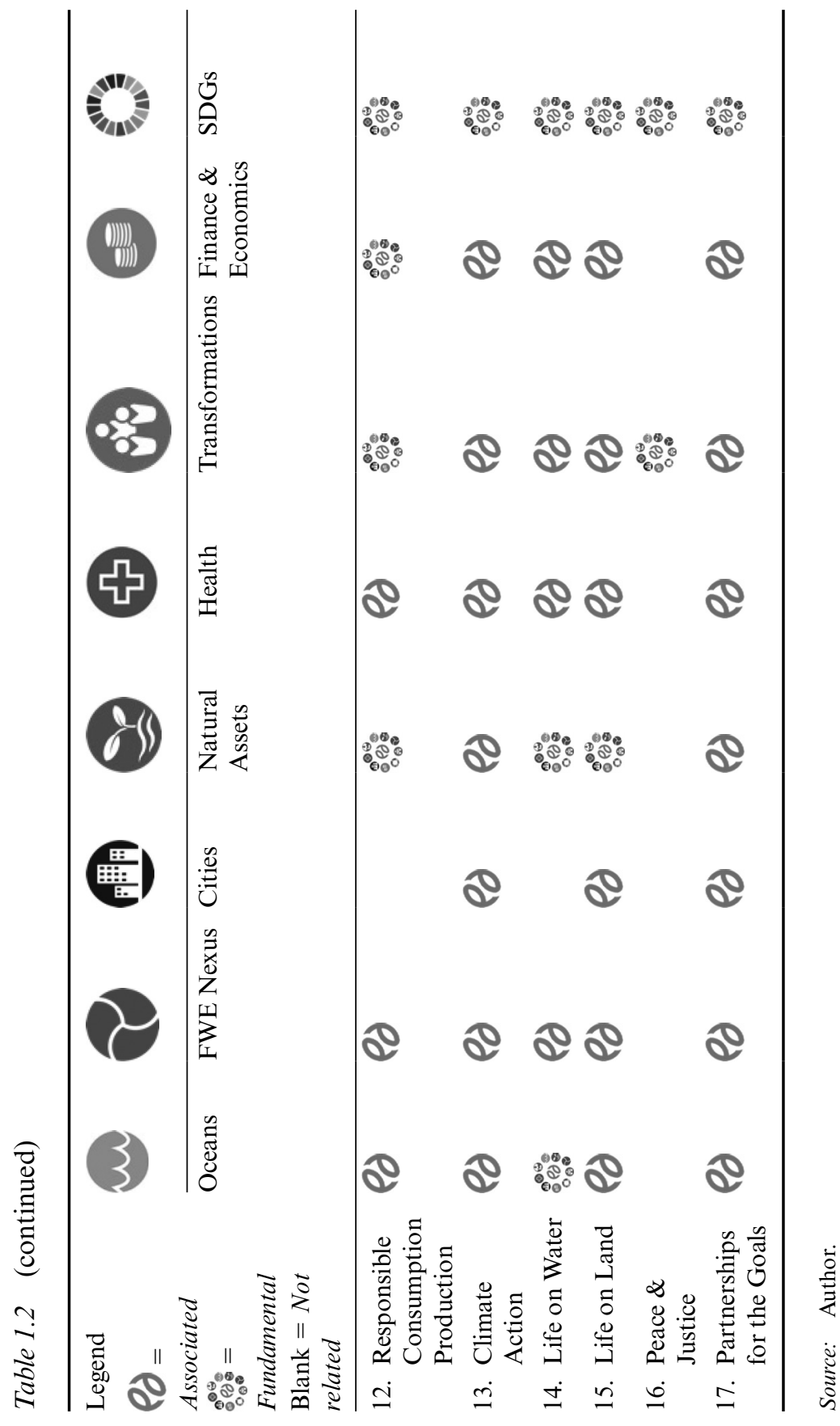


organizations (public and private) within a narrow frame of neoclassical economics. The challenge has now shifted to managing the planet itself. The business sector is being called to help implement sustainable development goals by managing food, water, and energy systems; urbanization processes and infrastructures; health; oceans; natural assets; financial and economic systems; and social innovations for transformation to sustainability for 9-10 billion people that will exist on earth by the middle of this century (StaffordSmith et al., 2016). Future Earth KANs can serve as a platform for engaging businesses in sustainable development on a scientific basis.

In developing new models of business, many new questions will need to be researched that have historically not been addressed by business researchers. In lieu of a conclusion, I list some topics for research that will be fruitfully examined.

- Business implications of global carbon budgets

- Policies and governance best practices for protecting the global commons

- Earth systems governance regimes for at risk areas (arctic, coral reefs, rainforests)

- Global and regional food-water-energy production tradeoffs

- Business-ecosocial contract

- Solving poverty/inequality through wage and basic income policies

- Decarbonization/dematerialization of the economy

- Intergenerational investing

- Corporate conservation bio \& cultural diversity

- Design of livable cities

- Sustainable extraction/recovery of natural assets

- Managing the oceans

- Gender equality at work, in communities, and across nations

- Education, training, capacity building

- Long-term design of work/jobs in "automated economies"

- Economic growth, post-growth prosperity

- Innovation - technological and social

- Urban Infrastructures and social innovation for livable cities

- Responsible consumption

- Developing the "sharing economy," co-living, co-working space, collaborative transport

- Sustainable peace and justice

- Partnerships and collaborations for Sustainable Development

- Sustainable investing, assessing corporate "planetary risks"

- Corporate time frames - quarterly, annual versus natural cycles

- Ownership and scale of operations in light of planetary boundaries 
This list is neither complete nor in any order of priority. It is just indicative of the different type of research that needs to be done from what is prevalent in most business schools today. One key point to note is that most of these topics are rarely addressed in business and organizational research. They represent substance and orientations different from concerns of profit-maximizing private corporations. However, private corporations, if they are to become key players in implementing SDGs, must develop a deep understanding of these topics. Also notable is the need for integrating business and social science concerns with the natural sciences tracking earth systems and life sciences variables. This creates a need for interdisciplinary and transdisciplinary research (Shrivastava et al., 2013). The KANs described in this chapter are an easy mechanism for business researchers to collaborate with natural scientists and business organizations.

\section{REFERENCES}

Business \& Sustainable Development Commission (2017). Better Business Better World. The Report of the Business \& Sustainable Development Commission.

Raworth, K. (2012). 'A safe and just space for humanity: can we live within the doughnut?', Oxfam Policy and Practice: Climate Change and Resilience, 8(1), $1-26$.

Rockstrom, J., Steffen, W., Noone, K., Persson, A., Chapin, F.S., Lambin, E.F., Lenton, T.M., Scheffer, M., Folke, C., Schellnhuber, H.J., Nykvist, B., de Wit, C.A., Hughes, T., van der Leeuw, S., Rodhe, H., Sorlin, S., Snyder, P.K., Costanza, R., Svedin, U., Falkenmark, M., Karlberg, L., Corell, R.W., Fabry, V.J., Hansen, J., Walker, B., Liverman, D., Richardson, K., Crutzen, P., and Foley, J.A. (2009). 'A safe operating space for humanity', Nature, 461, 472-75.

Shrivastava, P., Ivanaj, S. and Persson, S. (2013). 'Transdisciplinary Study of Sustainable Enterprise', Journal of Business Strategy and the Environment, 22(4), 230-44.

Stafford-Smith, M., Griggs, D., Gaffney, O., Ullah, F., Reyers, B., Kanie, N., Stigson, B., Shrivastava, P., Leach, M., and O'Connell, D. (2016). 'Integration: the key to implementing the Sustainable Development Goals', International Journal of Sustainability Sciences, DOI:10.1007/s11625-016-0383-3.

Steffen, W., Broadgate, W., Deutsch, L., Gaffney, O., and Ludwig, C. (2015b). 'The trajectory of the Anthropocene: the great acceleration', The Anthropocene Review, 2(1), 81-98.

Steffen, W., Richardson, K., Rockström, J., Cornell, S.E., Fetzer, I., Bennett, E.M., Biggs, R., Carpenter, S.R., de Vries, W., de Wit, C.A., Folke, C., Gerten, D., Heinke, J., Mace, G.M., Persson, L.M., Ramanathan,V., Reyers, B., and Sörlin, S. (2015a). 'Planetary boundaries: guiding human development on a changing planet', Science, 347(6223).

United Nations (2015). Transforming our World: The 2030 Agenda for Sustainable Development. New York, NY: United Nations. 